\title{
Maternal nicotinamide supplementation causes global DNA hypomethylation, uracil hypo-incorporation and gene expression changes in fetal rats
}

\author{
Yan-Jie Tian ${ }^{1} \dagger$, Ning Luo ${ }^{1} \dagger, \mathrm{Na}-\mathrm{Na}$ Chen ${ }^{1}$, Yong-Zhi Lun ${ }^{1}$, Xin-Yi Gu${ }^{2}$, Zhi $\mathrm{Li}^{1}$, Qiang Ma ${ }^{2 *}$ and \\ Shi-Sheng Zhou $^{1 *}$ \\ ${ }^{1}$ Institute of Basic Medical Sciences, Medical College, Dalian University, Dalian 116622, People's Republic of China \\ ${ }^{2}$ Department of Neurology, Affiliated Zhongshan Hospital of Dalian University, Dalian 116001, People's Republic of China
}

(Submitted 3 July 2013 - Final revision received 11 November 2013 - Accepted 18 November 2013 - First published online 10 February 2014)

\section{Abstract}

Recent evidence shows that excess nicotinamide can cause epigenetic changes in developing rats. The aim of the present study was to investigate the effects of maternal nicotinamide supplementation on the fetus. Female rats were randomised into four groups fed a standard chow diet (control group) or diets supplemented with $1 \mathrm{~g} / \mathrm{kg}$ of nicotinamide (low-dose group), $4 \mathrm{~g} / \mathrm{kg}$ of nicotinamide (high-dose group) or $4 \mathrm{~g} / \mathrm{kg}$ of nicotinamide plus $2 \mathrm{~g} / \mathrm{kg}$ of betaine (betaine group) for $14-16 \mathrm{~d}$ before mating and throughout the study. Fetal tissue samples were collected on the 20th day of pregnancy. Compared with the control group, the high-dose group had a higher fetal death rate, and the average fetal body weight was higher in the low-dose group but lower in the high-dose group. Nicotinamide supplementation led to a decrease in placental and fetal hepatic genomic DNA methylation and genomic uracil contents (a factor modifying DNA for diversity) in the placenta and fetal liver and brain, which could be completely or partially prevented by betaine. Moreover, nicotinamide supplementation induced tissue-specific alterations in the mRNA expression of the genes encoding nicotinamide $N$-methyltransferase, DNA methyltransferase 1, catalase and tumour protein p53 in the placenta and fetal liver. High-dose nicotinamide supplementation increased fetal hepatic $\alpha$-fetoprotein mRNA level, which was prevented by betaine supplementation. It is concluded that maternal nicotinamide supplementation can induce changes in fetal epigenetic modification and DNA base composition. The present study raises the concern that maternal nicotinamide supplementation may play a role in the development of epigenetic-related diseases in the offspring.

Key words: Maternal nutrient supplementation: Nicotinamide: Epigenetic changes: DNA hypomethylation

Growing evidence suggests that prenatal environment plays a role in non-communicable diseases, such as obesity, type 2 diabetes and CVD, which may involve epigenetic mechanisms, including DNA methylation ${ }^{(1,2)}$. The environmental sensitivity of the epigenome is viewed as an adaptive mechanism by which the developing organism adjusts its metabolic and homeostatic systems to suit the anticipated extrauterine environment $^{(3)}$. If this is the case, prenatal exposure to excess micronutrients (e.g. vitamins, minerals and trace elements) should also contribute to epigenetic changes.

Niacin (vitamin $\mathrm{B}_{3}$ ) is the generic term for nicotinic acid (present in plants) and nicotinamide (primarily found in animal tissues) ${ }^{(4)}$ and functions as the precursor of the coenzymes nicotinamide NAD and NADP, which are required for many oxidation-reduction reactions. In addition to its redox roles, $\mathrm{NAD}^{+}$is used as a substrate for the formation of mono-ADP-ribose, poly(ADP-ribose), cyclic ADP-ribose and acetyl ADP-ribose (Fig. 1), which also plays a role in a wide range of biological processes, including DNA repair, maintenance of genomic stability, apoptosis and necrosis ${ }^{(5,6)}$. Dietary niacin deficiency and pharmacological excesses of nicotinic acid or nicotinamide have dramatic effects on cellular NAD pools and tissue function ${ }^{(6,7)}$. To date, little is known about the effect of excess niacin exposure on fetal epigenetic changes.

Excess niacin mainly undergoes methylation-mediated degradation in the body ${ }^{(8,9)}$. Its methylated metabolites include $N^{1}$-methylnicotinamide, 2-pyridone $N^{1}$-methyl-2-pyridone-5-carboxamide and $N^{1}$-methyl-4-pyridone-3-carboxamide (Fig. 1).

\footnotetext{
Abbreviations: $A f p, \alpha$-fetoprotein; betaine group, diet supplemented with $4 \mathrm{~g} / \mathrm{kg}$ of nicotinamide plus $2 \mathrm{~g} / \mathrm{kg}$ of betaine; Cat, catalase; control group, standard chow diet; Dnmt-1, DNA methyltransferase 1; high-dose group, diet supplemented with $4 \mathrm{~g} / \mathrm{kg}$ of nicotinamide; low-dose group, diet supplemented with $1 \mathrm{~g} / \mathrm{kg}$ of nicotinamide; Nnmt, nicotinamide $N$-methyltransferase; Tp53, tumour protein p53.
}

*Corresponding authors: S.-S. Zhou, fax +86 411 87402053, email zhouss@ymail.com; Q. Ma, email mqiang2100@yahoo.com.cn 


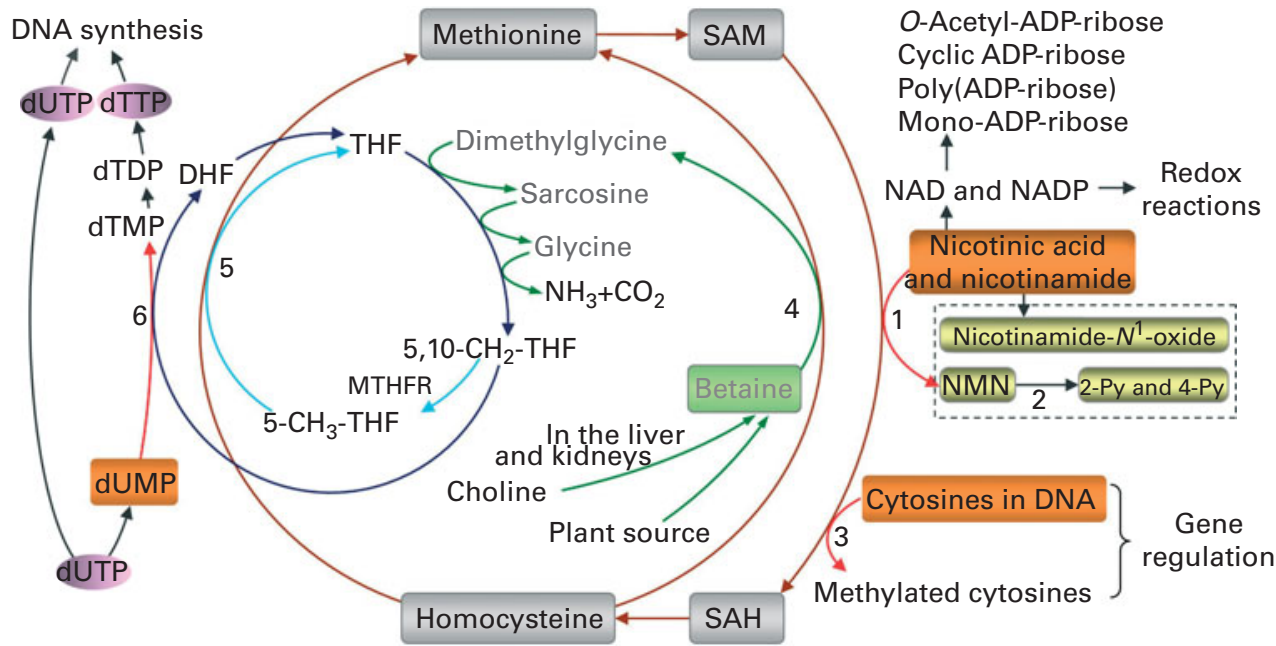

Fig. 1. The role of one-carbon metabolism in niacin (nicotinic acid and nicotinamide) degradation, DNA synthesis and DNA methylation. The function of the methionine cycle and folate cycle is to transfer one-carbon units from donors (primarily betaine and choline) to various receptors, such as nicotinamide, DNA and dUMP. Homocysteine generated from substrate methylation reactions can be remethylated to methionine through a betaine-dependent pathway or folatedependent pathway. 1, Nicotinamide $N$-methyltransferase; 2, aldehyde oxidase; 3, DNA methyltransferases; 4, betaine-homocysteine-methyltransferase; 5, methionine synthase; 6 , thymidylate synthase. 2-Py, $N^{1}$-methyl-2-pyridone-5-carboxamide; 4-Py, $N^{1}$-methyl-4-pyridone-3-carboxamide; DHF, dihydrofolate; dTDP, deoxythymidine diphosphate; dTMP, deoxythymidine monophosphate; dTTP, deoxythymidine triphosphate; dUMP, deoxyuridine monophosphate; dUTP, deoxyuridine triphosphate; MTHFR, 5,10-methylenetetrahydrofolate reductase; NMN, $N^{1}$-methylnicotinamide; SAH, S-adenosylhomocysteine; SAM, $S$-adenosylmethionine; THF, tetrahydrofolate.

As shown in Fig. 1, the role of a methylation reaction is to transfer a labile methyl group from a methyl donor to a substrate (e.g. nicotinamide and DNA), and all S-adenosylmethionine-dependent methylation reactions share the same pool of methyl groups. An increase in methylation reactions will increase the consumption of labile methyl groups (e.g. derived from choline and betaine, which are a non-renewable resource) rather than of methyl-group-transfer mediators (such as methionine and folate, which can be repeatedly used in the methionine cycle). Thus, the methylation of excess niacin may affect other methylation reactions by competing for the limited methyl-group pool. A previous study ${ }^{(10)}$ in our laboratory revealed that nicotinamide ( $100 \mathrm{mg}$, orally) led to a significant decrease in the level of plasma betaine in healthy subjects. Long-term nicotinamide supplementation ( $4 \mathrm{~g} / \mathrm{kg}$ diet) in developing rats induced a significant decrease in the level of plasma betaine and a significant increase in choline level associated with a decrease in hepatic global DNA methylation (an epigenetic change) and uracil content in genomic $\mathrm{DNA}^{(11)}$. The results suggest that excess nicotinamide might disturb one-carbon metabolism and uracil incorporation into DNA. Moreover, excess nicotinamide increases the generation of reactive oxygen species ${ }^{(12,13)}$, which can cause oxidative tissue damage associated with alterations in the expression of genes related to methyl-group metabolism, reactive oxygen species clearance and cell damage ${ }^{(11)}$. Therefore, we hypothesise that prenatal high nicotinamide exposure may induce fetal epigenetic changes and that betaine, a major methyl donor ${ }^{(14,15)}$, may mitigate the effect of nicotinamide. The aim of the present study was to address the effects of maternal nicotinamide supplementation with or without betaine on rat fetal development, fetal epigenetic patterns, uracil incorporation into DNA and the mRNA expression patterns of the genes encoding nicotinamide $N$-methyltransferase (Nnmt), DNA methyltransferase 1 (Dnmt-1), catalase (Cat), tumour protein p53 (Tp53) and $\alpha$-fetoprotein (Afp), which are respectively related to nicotinamide degradation, DNA methylation (Fig. 1), reactive oxygen species detoxification, DNA damage ${ }^{(11)}$ and hepatic injury ${ }^{(16)}$.

\section{Materials and methods}

\section{Animal and experimental design}

All protocols for animal experiments were conducted according to the NIH Guide for Care and Use of Laboratory Animals, and approved by the Animal Care and Use Committee of Dalian University. Sprague-Dawley rats (from Dalian Medical University Animal Center) aged $70-90 \mathrm{~d}$ were used in the study. They were subjected to a cycle of $12 \mathrm{~h}$ of light followed by $12 \mathrm{~h}$ of dark at an ambient temperature of $22^{\circ} \mathrm{C}$, and they had free access to tap water and standard chow diet. After 1 week of acclimatisation, female rats were randomised into four groups and fed ad libitum with standard chow diet (control group, $n$ 16) or diets supplemented with $1 \mathrm{~g} / \mathrm{kg}$ of nicotinamide (Sigma) (low-dose group, $n 18), 4 \mathrm{~g} / \mathrm{kg}$ of nicotinamide (high-dose group, $n$ 19) or $4 \mathrm{~g} / \mathrm{kg}$ of nicotinamide plus $2 \mathrm{~g} / \mathrm{kg}$ of betaine (Sigma; betaine group, $n$ 15) for $14-16 \mathrm{~d}$ before mating and throughout the study. There was no statistically significant difference in the body weight between groups at mating. Daily vaginal smears were obtained from all females to determine stages of the oestrous cycle. When in proestrus, two female rats were placed in a cage with one male overnight. The presence of spermatozoa 
in the vaginal smear the following morning was designated as day 1 of pregnancy. After mating, the females were removed and housed separately. Each rat was carefully observed throughout pregnancy and weight gain was monitored and recorded daily. At day 20 of gestation, rats were anaesthetised with diethyl ether, and fetuses and placentas were released from the uterus. The offspring and placentas were transferred to a Petri dish containing normal saline solution. The number of fetuses and stillbirths was recorded and each fetus and placenta was weighed individually (Table 1). The samples of placenta and fetal liver and whole brain were collected and transferred immediately to liquid $\mathrm{N}_{2}$, and kept at $-80^{\circ} \mathrm{C}$.

\section{Genomic DNA methylation assay}

Genomic DNA methylation was measured as described previously ${ }^{(11)}$. Briefly, genomic DNA was extracted from the placenta and fetal liver samples. Contaminating RNA was removed by incubation with RNase A $(100 \mu \mathrm{g} / \mathrm{ml}$; Takara Biotechnology (Dalian) Company Limited) and RNase T1 (2000 units $/ \mathrm{ml}$; Sigma) for $2 \mathrm{~h}$ at $37^{\circ} \mathrm{C}$. Following the incubation, DNA was extracted using phenol-chloroform-isoamyl alcohol, precipitated with ethanol and resuspended in $100 \mu \mathrm{l}$ DNase I digestion buffer (10 mm-Tris-HCl, pH 7.2, 0.1 mm-

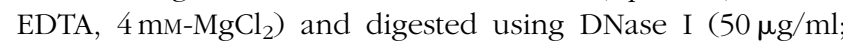
Sigma) for $14 \mathrm{~h}$ at $37^{\circ} \mathrm{C}$. DNA was further digested using Nuclease P1 $\left(50 \mu \mathrm{g} / \mathrm{ml}\right.$; Sigma) for $7 \mathrm{~h}$ at $37^{\circ} \mathrm{C}$ in the presence of two volumes of $30 \mathrm{~mm}$-sodium acetate $(\mathrm{pH} 5 \cdot 2)$ and $1 \mathrm{~mm}-\mathrm{ZnSO}_{4}$. Solid debris was removed by centrifugation using a spin column with a $0.45 \mu \mathrm{m}$ filter. Hydrolysed DNA was analysed for cytosine methylation content by HPLC ${ }^{(11)}$. The amount of DNA cytosine methylation was calculated by the following formula:

$$
\begin{aligned}
& \text { Amount of DNA cytosine methylation } \\
& =\frac{\text { methylated cytosines }}{\text { total cytosines in DNA }} \times 100(\%) .
\end{aligned}
$$

\section{Measurement of uracil levels in DNA}

Uracil levels in DNA were determined as described previously $^{(11)}$. Genomic DNA was extracted using a high-salt method $^{(17)}$ from placenta and fetal liver and whole brain samples. After extraction, $50 \mu \mathrm{g}$ of DNA were treated with two units of uracil DNA glycosylase in Tris-EDTA buffer at $37^{\circ} \mathrm{C}$ for $1 \mathrm{~h}$. After incubation, $100 \mathrm{pg}\left[{ }^{15} \mathrm{~N}_{2}\right]$ uracil (Sigma) was added as an internal standard, and the samples were dried in a speed vac concentrator. Uracil and the internal standard were derivatised by adding $50 \mu \mathrm{l}$ acetonitrile, $10 \mu \mathrm{l}$ triethylamine and $1 \mathrm{ml}$ 3,5-bis(trifluoro-methyl)benzyl bromide (Sigma) at $30^{\circ} \mathrm{C}$ for $25 \mathrm{~min}$, followed by the addition of $50 \mu \mathrm{l}$ of water. The derivative was extracted into $100 \mu \mathrm{l}$ isooctane (Sigma). A GC-MS ${ }^{(11)}$ was used to measure the levels of uracil in DNA.

\section{Real-time quantitative $P C R$}

Real-time quantitative PCR was performed as described previously $^{(11)}$. Total RNA of the placenta and fetal liver samples was extracted with TRIzol (Invitrogen) according to the manufacturer's protocol. Extracted RNA (1-2 $\mu \mathrm{g})$ was reverse-transcribed in a $20 \mu \mathrm{l}$ reaction with both oligo (dT) $(50 \mu \mathrm{M})$ and Random 6 mers using the PrimeScript RT Master Mix (Takara Biotechnology (Dalian) Company Limited) on an ABI Gene Amp PCR System 9700 (Applied Biosystems). Complementary DNA fragments were amplified using SYBR Premix Ex TaqTM II (Takara Biotechnology (Dalian) Company Limited) on an ABI Prism 7500 sequence detector (Applied Biosystems). Thermal cycling conditions consisted of an initial denaturation step at $95^{\circ} \mathrm{C}$ for $10 \mathrm{~min}$ and then forty cycles of $95^{\circ} \mathrm{C}$ for $10 \mathrm{~s}$ and $60^{\circ} \mathrm{C}$ for $20 \mathrm{~s}$. The primer sequences for the genes studied are listed in Supplementary Table S1 (available online). Each sample was run in triplicate and the housekeeping gene glyceraldehyde phosphate dehydrogenase (GAPDH) was used as an internal control. Relative mRNA expression levels were determined using the $2^{-\Delta \Delta C t}$ method as described by Livak \& Schmittgen ${ }^{(18)}$.

\section{Statistical analysis}

Data are presented as means with their standard errors. Statistical analysis was performed by $\chi^{2}$ test, one-way ANOVA followed by Student Newman-Keuls post hoc test, or paired Student's $t$ test using SPSS version 11.5 software (SPSS, Inc.). Differences were considered significant at $P<0 \cdot 05$.

Table 1. Reproductive performance of rats

\begin{tabular}{lcccc}
\hline & Control group & Low-dose group & High-dose group & Betaine group \\
\hline Number of female rats & 16 & 18 & 19 & 15 \\
Number of pregnancies & 13 & 16 & 12 & 12 \\
Pregnancy rate (\%) & 81.25 & 88.89 & 63.16 & 80 \\
Number of fetuses & 156 & 188 & 129 & 121 \\
Number of fetal death & 0 & 1 & 9 & 0 \\
Stillbirth rate (\%) & 0 & 0.53 & $6.98^{*}$ & $0+$ \\
\hline
\end{tabular}

Control group, standard chow diet; low-dose group, diet supplemented with $1 \mathrm{~g} / \mathrm{kg}$ of nicotinamide; high-dose group, diet supplemented with $4 \mathrm{~g} / \mathrm{kg}$ of nicotinamide; betaine group, diet supplemented with $4 \mathrm{~g} / \mathrm{kg}$ of nicotinamide plus $2 \mathrm{~g} / \mathrm{kg}$ of betaine.

${ }^{*}$ Mean value was significantly different from that of the control group $\left(\chi^{2}\right.$ test; $\left.P<0.01\right)$.

$\dagger$ Mean value was significantly different from that of the high-dose group $\left(\chi^{2}\right.$ test; $\left.P<0.05\right)$. 


\section{Results}

\section{Effects of maternal nicotinamide supplementation on} fetal development

Maternal nicotinamide supplementation at the doses used induced a significant decrease in placental weight, which was not affected by co-supplementation with betaine (Fig. 2(a)). The average body weight is $4.5 \%$ higher in the low-dose group and $11.8 \%$ lower in the high-dose group than in the control group. The effect of high-dose nicotinamide supplementation on body weight could be partially reversed by betaine (Fig. 2(b)). Changes in the average body length followed a similar trend as the body weight: lowdose nicotinamide supplementation slightly increased fetal body length (but without statistically significant difference, $P=0.308)$, while high-dose nicotinamide supplementation decreased it $(P<0.05)$ (Fig. 2(c))

\section{Changes in genomic DNA methylation}

DNA methylation refers to the addition of a methyl group to cytosine in a cytosine-guanine dinucleotide pair ${ }^{(19)}$. The present study compared the levels of methylated cytosines in DNA between groups. As shown in Fig. 3(a), both the lowdose and high-dose groups showed a decrease in the level of global DNA methylation in the placenta and fetal liver. The level of DNA methylation in the placenta and fetal liver of the high-dose group decreased by 33.1 and $59.1 \%$, respectively, suggesting that fetal liver is more susceptible to nicotinamide than that of placenta. Betaine $(2 \mathrm{~g} / \mathrm{kg}$ diet $)$ partially prevented the effect of high-dose nicotinamide supplementation on the level of DNA methylation in the placenta and fetal liver.

\section{Effects of maternal nicotinamide supplementation on} global uracil contents

Fig. 3(b) shows genomic uracil contents in the placenta and fetal liver and brain. Interestingly, in the control group, the values of global uracil contents in the brain were significantly higher than that of fetal hepatic tissue $(P<0 \cdot 05$, paired Student's $t$ test). Maternal nicotinamide supplementation at the doses studied led to a decrease in genomic uracil contents in the tissues examined. Statistical differences were found between the control group and the large-dose group (Fig. 3(b)). Betaine could completely (in the placenta and fetal liver) or partially (in the fetal brain) prevent a high-dose nicotinamide-induced decrease in genomic uracil contents

\section{Nicotinamide-induced changes in fetal gene expression}

The present study further investigated the effects of maternal nicotinamide supplementation on the mRNA expression levels of Nnmt, Dnmt-1, Cat, Tp53 and Afp. The results showed that $N n m t$ mRNA expression was higher in the placenta than in the fetal liver of the control group $(P<0 \cdot 05$, paired Student's $t$ test; Fig. 4(a)), suggesting that under physiological conditions, the placenta might play a major role in the degradation of nicotinamide. There was a decreasing trend in the mRNA of placental Nnmt and Dnmt-1 associated with decreased mRNA levels of Tp53, but an increase in the mRNA of fetal hepatic Nnmt and Dnmt-1 associated with increased mRNA levels of Tp53 in the two nicotinamidesupplemented groups, compared with the control group (Fig. 4(a), (b) and (d), respectively). Betaine could completely or partially prevent nicotinamide-induced changes in the mRNA expression of Nnmt and Dnmt-1. Maternal nicotinamide supplementation induced a significant increase in placental Cat mRNA levels, which was further enhanced by betaine. In contrast, increased hepatic Cat mRNA expression was observed only in the large-dose group (though not significantly different from the control group), which could be prevented by betaine (Fig. 4(c)). The expression of $A f p$ mRNA in the large-dose group was significantly higher than that in the control group (15.5 (SEM 5.5) v. 2.83 (SEM 0.65), both $n 10, P<0.05$, Student-Newman-Keuls post hoc test), while the relative expression level in the betaine group
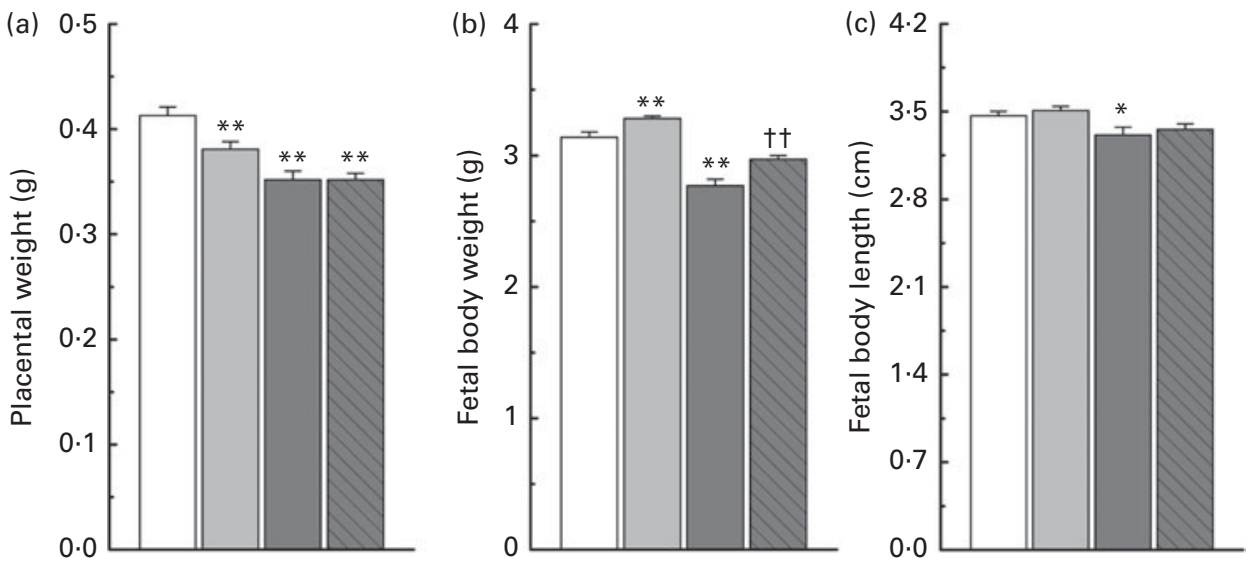

Fig. 2. Effects of maternal nicotinamide (NM) supplementation with or without betaine on placental weight (a) and fetal rat body weight (b) and body length (c). $\square$, Control diet ( $n$ 156); $\square, 1 \mathrm{~g} \mathrm{NM} / \mathrm{kg}$ diet ( $n$ 188); $\square, 4 \mathrm{~g} \mathrm{NM} / \mathrm{kg}$ diet $(n$ 129); $₫, 4 \mathrm{~g} \mathrm{NM}$ plus $2 \mathrm{~g}$ betaine $/ \mathrm{kg}$ diet $(n$ 121). Values are means, with their standard errors represented by vertical bars. Mean value was significantly different from that of the control group: ${ }^{\star} P<0.05 ;{ }^{* \star} P<0.01$ (ANOVA with Student-Newman-Keuls post hoc test). †† Mean value was significantly different from that of the $4 \mathrm{~g} \mathrm{NM} / \mathrm{kg}$ diet group $(P<0.05$; ANOVA with Student-Newman-Keuls post hoc test). 

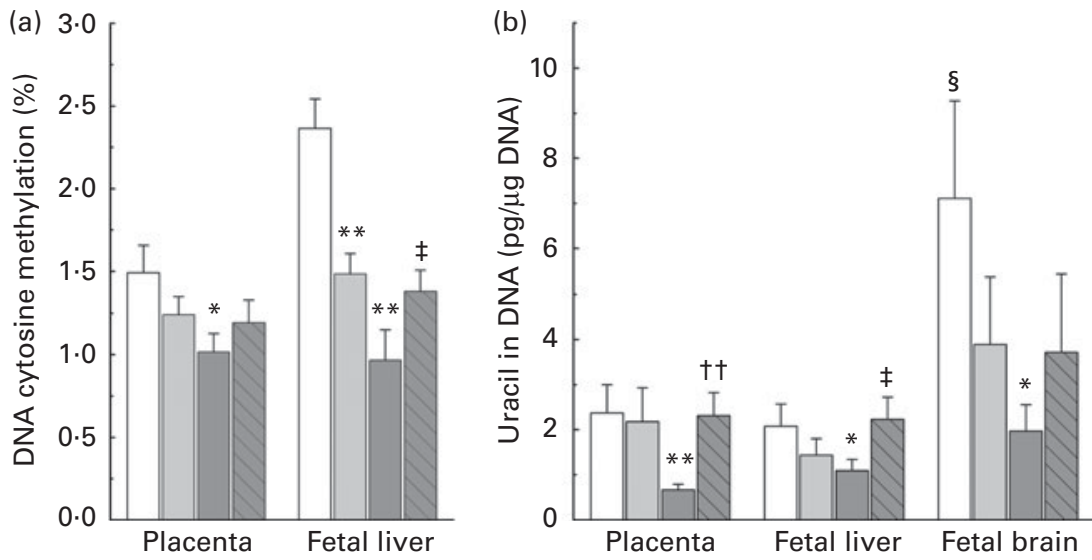

Fig. 3. Effects of maternal nicotinamide (NM) supplementation with or without betaine on genomic DNA methylation (a) and genomic uracil contents (b). $\square$, Control diet; $\square, 1 \mathrm{~g} \mathrm{NM} / \mathrm{kg}$ diet; $\square, 4 \mathrm{~g} \mathrm{NM} / \mathrm{kg}$ diet; $\mathbb{\Xi}, 4 \mathrm{~g} \mathrm{NM}$ plus $2 \mathrm{~g}$ betaine/ $\mathrm{kg}$ diet. Values are means ( $n 10$ litters per group), with their standard errors represented by vertical bars. Mean value was significantly different from that of the control group: ${ }^{*} P<0.05,{ }^{* *} P<0.01$ (ANOVA with Student-Newman-Keuls post hoc test). †† Mean value was significantly different from that of the $4 \mathrm{~g} \mathrm{NM} / \mathrm{kg}$ diet group $(P<0.01$; ANOVA with Student-Newman-Keuls post hoc test). $¥$ Mean value was significantly different from that of the $4 \mathrm{~g} \mathrm{NM} / \mathrm{kg}$ diet group $(P<0.05$; ANOVA with Student-Newman-Keuls post hoc test). § Mean value was significantly different from that for the fetal liver of the same diet group $(P<0.05$; paired Student's $t$ test).

$(2 \cdot 12($ SEm $0 \cdot 77), n$ 10) was similar to that of the control group, indicating that the effect of large-dose nicotinamide supplementation on $A f p$ mRNA expression could be completely prevented by betaine.

\section{Discussion}

The present study found that maternal nicotinamide supplementation increased fetal body weight at the dose of $1 \mathrm{~g} / \mathrm{kg}$ diet, but decreased fetal body weight at the dose of $4 \mathrm{~g} / \mathrm{kg}$ diet. Despite differences in fetal body weight, both the low-dose and high-dose groups showed a decrease in the levels of uracil and methylated cytosines in fetal liver DNA, which was associated with an increasing trend in the mRNA expression of Nnmt and Dnmt-1. These results suggest that both low and high birth weight may be associated with similar epigenetic changes. Although the effects of maternal nicotinamide supplementation on fetal development may involve multiple factors, e.g. NAD-dependent processes, the changes in DNA methylation and DNA uracil contents might be mainly related to disturbed one-carbon metabolism, since the effects of nicotinamide supplementation at the dose of $4 \mathrm{~g} / \mathrm{kg}$ diet were completely or partially prevented by betaine ( $2 \mathrm{~g} / \mathrm{kg}$ diet).

As can be seen in Fig. 1, betaine, when completely catabolised, can donate one methyl group directly to homocysteine to form methionine (betaine-dependent remethylation pathway) and three one-carbon units for the conversion of three molecules of tetrahydrofolate to three molecules of 5,10-methylenetetrahydrofolate. Besides being used for the synthesis of deoxythymidine monophosphate from deoxyuridine monophosphate, 5,10-methylenetetrahydrofolate can be further converted to 5-methyltetrahydrofolate and then used in the remethylation of homocysteine to methionine (folatedependent remethylation pathway). Thus, in theory, betaine at the dose of $2 \mathrm{~g} / \mathrm{kg}$ diet should meet the increased demand of methyl groups by nicotinamide at the dose of $4 \mathrm{~g} / \mathrm{kg}$ diet, since both chemicals have a similar molar mass (betaine $117 \cdot 1 v$. nicotinamide $122 \cdot 1$ ). Unexpectedly, betaine at the dose used only partially prevented high-dose nicotinamideinduced global DNA hypomethylation, but completely prevented the decrease in genomic uracil contents in the placenta and fetal liver. These data suggest that betaine may play a crucial role not only in DNA methylation but also in uracil incorporation into DNA. The latter may involve a change in the synthesis of deoxythymidine monophosphate, since decreased betaine-dependent homocysteine remethylation may enhance the expression of methionine synthase, as observed in our previous study ${ }^{(11)}$, suggesting that there is a compensation in the folate cycle, which is a well-known factor promoting the synthesis of deoxythymidine monophosphate and decreasing uracil incorporation during DNA synthesis (Fig. 1). In addition, the present result showed betaine significantly enhanced the placental mRNA expression of Cat. This suggests that betaine may play a role in the detoxification function of the placenta.

The function of DNA methylation is to help maintain chromosomal stability ${ }^{(19-21)}$. Increasing evidence suggests that decreased DNA methylation may have an impact on the predisposition to pathological states and the development of diseases, especially cancer $^{(22)}$. Besides decreased global DNA methylation, cancer is also associated with high levels of expression of DNA methyltransferases ${ }^{(23)}$ and the re-expression of some fetal genes, e.g. expression of $A f p$ in liver cancer ${ }^{(24)}$. Interestingly, many cancers, such as gastric cancer $^{(25)}$, renal cancer ${ }^{(26)}$, thyroid cancer $^{(27)}$, bladder cancer $^{(28)}$ and lung cancer ${ }^{(29)}$, have been found to have an increased expression of Nnmt. A possible explanation for the association between global hypomethylation and increased expression of methyltransferases in cancer may be a compensatory mechanism in response to methyl-pool depletion. As observed in the present and previous studies ${ }^{(11)}$, 

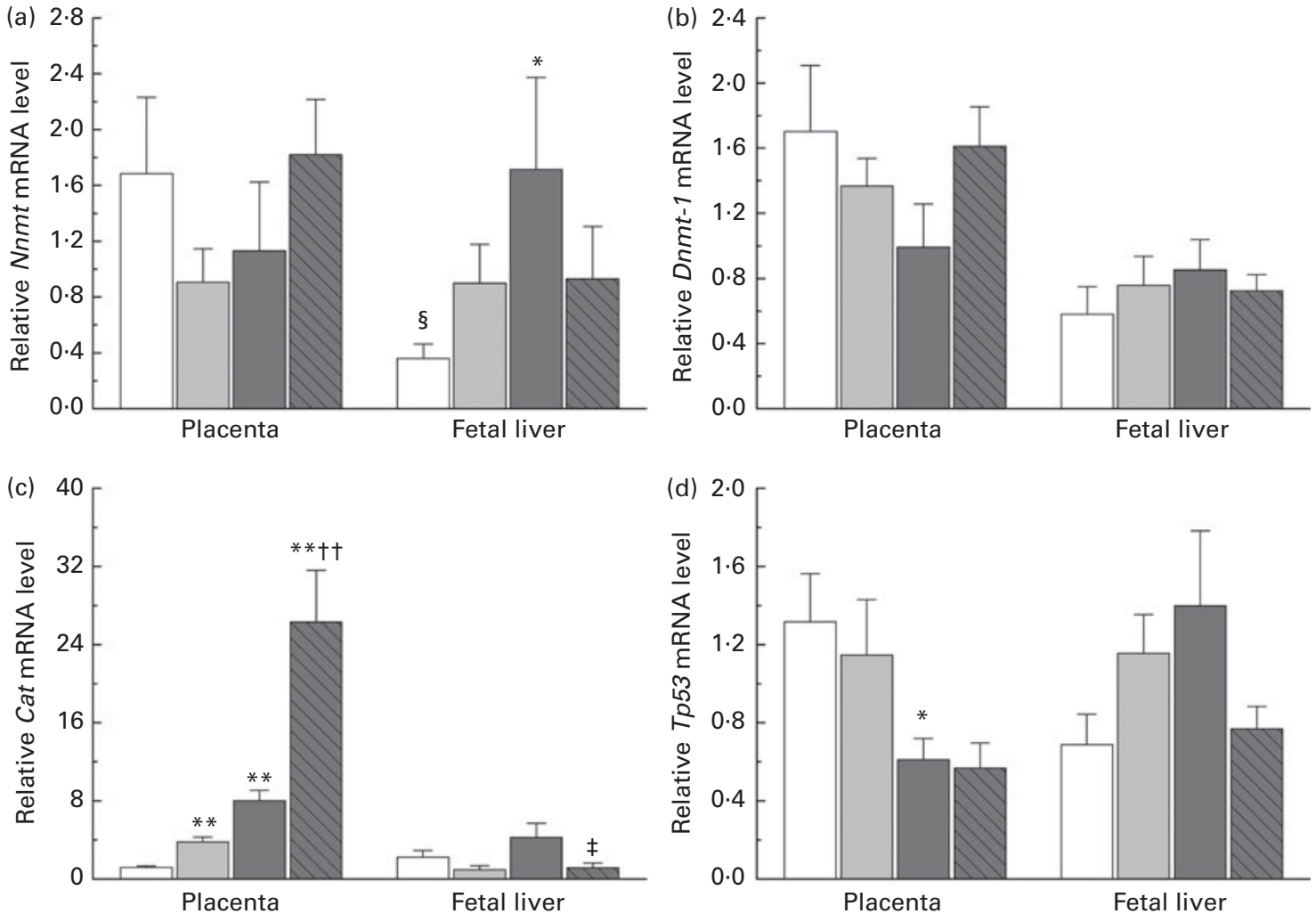

Fig. 4. Maternal nicotinamide (NM) and betaine supplementation-induced changes in the mRNA expression of genes encoding nicotinamide $N$-methyltransferase (Nnmt) (a), DNA methyltransferase 1 (Dnmt-1) (b), catalase (Cat) (c) and tumour protein p53 (Tp53) (d) in placenta and fetal liver. $\square$, Control diet; $\square$, $1 \mathrm{~g} \mathrm{NM/kg}$ diet; $\square, 4 \mathrm{~g} \mathrm{NM} / \mathrm{kg}$ diet; $₫, 4 \mathrm{~g} \mathrm{NM}$ plus $2 \mathrm{~g}$ betaine/kg diet. Values are means ( $n 8-10$ from eight to ten litters), with their standard errors represented by vertical bars. Mean value was significantly different from that of the control group: ${ }^{\star} P<0.05$, ${ }^{\star \star} P<0.01$ (ANOVA with Student-Newman-Keuls post hoc test). $\dagger \dagger$ Mean value was significantly different from that of the $1 \mathrm{~g} \mathrm{NM} / \mathrm{kg}$ diet group $(P<0.01$; ANOVA with Student-Newman-Keuls post hoc test). $\ddagger$ Mean value was significantly different from that of the $4 \mathrm{~g} \mathrm{NM} / \mathrm{kg}$ diet group $(P<0.05$; ANOVA with Student-Newman-Keuls post hoc test). $\S$ Mean value was significantly different from that for the placenta of the same diet group $(P<0.05$; paired Student's $t$ test).

excess nicotinamide-induced changes in DNA methylation and in the expression of $N n m t$ and Dnmt-1 are similar to the manifestations of cancer, suggesting that high nicotinamide intake might contribute to the development of cancer.

While the physiological roles of genome uracil are not fully understood, evidence suggests that genome uracil may be a tool to modify DNA for diversity or degradation ${ }^{(30)}$. For example, in B-cells, uracil in DNA is a physiological intermediate in acquired immunity ${ }^{(31)}$. Focher et al. ${ }^{(32)}$ found that around the time of birth in rats, there is a rapid decrease in uracil DNA-glycosylase (the enzyme responsible for the removal of uracil from DNA) in brain neurons. The data from Drosophila also show that uracil is accumulated in genomic DNA of larval tissues during larval development, whereas DNA from imaginal tissues contains much less uracil ${ }^{(33)}$. Thus, it seems that the high genomic uracil contents in fetal brain observed in the present study may be intentional rather than a mistake. Given that (1) the brain grows faster than any other part of the body in the fetal period, and (2) DNA uracil content in the fetal brain is higher than that of the fetal liver, we assume that high brain genomic uracil levels may be the molecular basis of brain plasticity. Evidence supporting this assumption is the finding that imprinting stimuli can decrease the rate of uracil incorporation into macromolecules in the anterior part of the forebrain roof in the chick brain, which suggests that uracil incorporation is closely linked with the learning process ${ }^{(34,35)}$. Thus, an excess nicotinamide-induced decrease in genomic uracil contents may reduce brain plasticity and subsequent brain function. Indeed, Young et al. $^{(36)}$ found that high-dose nicotinamide supplementation may cause learning disabilities in rats.

Based on rats consuming about $20 \mathrm{~g}$ diet $/ \mathrm{d}^{(37)}$, the daily exposure level to nicotinamide was about $80 \mathrm{mg} / \mathrm{kg}$ in the low-dose group and about $320 \mathrm{mg} / \mathrm{kg}$ in the high-dose group. According to the formula for dose translation based on the body surface area (human equivalent dose $(\mathrm{mg} / \mathrm{kg})=$ animal dose $(\mathrm{mg} / \mathrm{kg}) \times$ animal $\mathrm{km}$ factor/human $\mathrm{km}$ factor $)^{(38)}$, the human equivalent doses are about 13 and $52 \mathrm{mg} / \mathrm{kg}$, respectively, which equals to approximately 780 and $3000 \mathrm{mg}$ niacin for a $60 \mathrm{~kg}$ person, respectively. These doses are within the range used in the treatment or prevention of some human disorders, such as hyperlipidaemia ${ }^{(39)}$, type 1 diabetes $^{(40)}$ and anxiety symptoms ${ }^{(41)}$. Thus, there is the possibility that such levels of niacin exposure may occur in some pregnant women, although this may be rare. It is worth noting that excess nicotinamide cannot be eliminated in the urine in human subjects ${ }^{(8)}$ due to the reabsorption in the renal tubule ${ }^{(42)}$, but can be efficiently eliminated in the urine 
in rats ${ }^{(43)}$. For example, Shibata ${ }^{(43)}$ found that when a large amount of nicotinamide $(500 \mathrm{mg} / \mathrm{kg}$ body weight $)$ was intraperitoneally injected into rats, $32 \%$ of the dose was excreted as nicotinamide, $16 \%$ as methylated derivatives of nicotinamide, $10 \%$ as nicotinuric acid, $5 \%$ as nicotinic acid during day 1 after the injection. These observations suggest that human subjects may be more susceptible to nicotinamide toxicity than rats.

In addition, the present study found that the infertility rate and fetal death rate are higher in the large-dose group than in the control group. Also, there are limited data from human studies suggesting that micronutrient supplementation might have an adverse effect on human reproduction. For example, the results of the Medical Research Council Vitamin Study showed a decreasing trend in the pregnancy rate with the increase in the number of vitamins supplemented. The pregnancy rate (number of completed pregnancies/number of women randomised) of the control group (without vitamin supplements), the folic acid group $(4 \mathrm{mg} / \mathrm{d})$, the multivitamin group (daily supplement containing vitamin A $1.2 \mathrm{mg}$ (4000 IU), vitamin $\mathrm{D} 10 \mu \mathrm{g}$ (400 IU), vitamin $\mathrm{B}_{1} 1-5 \mathrm{mg}$, vitamin $\mathrm{B}_{2}$ $1.5 \mathrm{mg}$, vitamin $\mathrm{B}_{6} 10 \mathrm{mg}$, vitamin $\mathrm{C} 40 \mathrm{mg}$ and nicotinamide $15 \mathrm{mg}$ ) and the folic acid plus multivitamin group was 76.21\% (346/454), 75.28\% (338/449), 74.83\% (339/453) and $73.54 \%$ (339/461), respectively ${ }^{(44)}$. The data from the Irish Vitamin Study Group also indicated a similar trend, i.e. the pregnancy rate of the folic acid group, the multivitamin group and the folic acid plus multidimensional group was $80 \cdot 87,79 \cdot 83$ and $77 \cdot 5 \%$, respectively ${ }^{(45)}$. Moreover, the data from the Hungarian randomised controlled trial of periconceptional multivitamin supplementation showed that the rate of fetal death (fetal deaths/fetal deaths plus live births) was $12.4 \%(297 / 2394)$ in the group receiving supplements of both multivitamin and trace elements, which was higher than that in the group that did not receive multivitamin supplements $(11.3 \% ; 261 / 2310)^{(46)}$. More inconceivably, the Hungarian cohort-controlled trial of periconceptional multivitamin and trace-element supplementation found that the proportion of previous fetal deaths (about 98\% miscarriages) in the cohort of mothers recruited from the participants of the Hungarian Periconceptional Service was 2.1 times higher than that of the cohort of mothers recruited from routine-care subjects, and the rate of infant mortality was $3 \cdot 1$ times higher in previously born infants of supplemented mothers ${ }^{(47)}$. Since the participants of the Hungarian Periconceptional Service received periconceptional supplementation with multivitamin and/or trace elements ${ }^{(48)}$, it is possible that the increased rates of fetal and infant death might be related to excess micronutrients.

It is concluded that maternal nicotinamide supplementation may cause fetal epigenetic changes and uracil hypoincorporation by disturbing one-carbon metabolism, which may be a factor leading to chromosome instability and disturbing the plasticity in early development. The role of maternal nicotinamide supplementation in the development of non-communicable diseases in the offspring needs to be further studied.

\section{Supplementary material}

To view supplementary material for this article, please visit http://dx.doi.org/10.1017/S0007114513004054

\section{Acknowledgements}

The present study was supported by the National Natural Science Foundations of China (S.-S. Z., grant no. 31140036; X.-Y. G., grant no. 81000575) and the Foundation of Key Laboratory of Education Department of Liaoning Province (Y.-Z. L., grant no. L2012441). The funders had no role in the design, analysis or writing of this article.

The authors' contributions are as follows: S.-S. Z. designed the research and drafted the manuscript; Y.-J. T., N. L., N.-N. C. and Z. L. contributed to the data acquisition and analysis; Q. M., X.-Y. G. and Y.-Z. L. contributed to the analysis and interpreted the study results. All authors read and approved the final manuscript.

The authors have no conflicts of interest to declare.

\section{References}

1. Burdge GC \& Lillycrop KA (2010) Nutrition, epigenetics, and developmental plasticity: implications for understanding human disease. Annu Rev Nutr 30, 315-339.

2. Barouki R, Gluckman PD, Grandjean P, et al. (2012) Developmental origins of non-communicable disease: implications for research and public health. Environ Health 11, 42 .

3. Boekelheide K, Blumberg B, Chapin RE, et al. (2012) Predicting later-life outcomes of early-life exposures. Environ Health Perspect 120, 1353-1361.

4. EFSA Panel on Additives and Products or Substances used in Animal Feed (FEEDAP) (2012) Scientific opinion on the safety and efficacy of niacin (nicotinamide) as feed additive for all animal species based on a dossier submitted by Agrinutrition BV. EFSA J 10, 2731.

5. Bürkle A (2005) Poly(ADP-ribose). The most elaborate metabolite of $\mathrm{NAD}^{+}$. FEBS J 272, 4576-4589.

6. Kirkland JB (2009) Niacin status, NAD distribution and ADPribose metabolism. Curr Pharm Des 15, 3-11.

7. Magni G, Orsomando G, Raffelli N, et al. (2008) Enzymology of mammalian NAD metabolism in health and disease. Front Biosci 13, 6135-6154.

8. Ellinger P \& Kader MM (1949) Nicotinamide metabolism in mammals. Biochem J 44, 77-87.

9. Mrochek JE, Jolley RL, Young DS, et al. (1976) Metabolic response of humans to ingestion of nicotinic acid and nicotinamide. Clin Chem 22, 1821-1827.

10. Sun WP, Li D, Lun YZ, et al. (2012) Excess nicotinamide inhibits methylation-mediated degradation of catecholamines in normotensives and hypertensives. Hypertens Res 35, 180-185.

11. Li D, Tian YJ, Guo J, et al. (2013) Nicotinamide supplementation induces detrimental metabolic and epigenetic changes in developing rats. Br J Nutr 110, 2156-2164.

12. Zhou SS, Li D, Sun WP, et al. (2009) Nicotinamide overload may play a role in the development of type 2 diabetes. World $J$ Gastroenterol 15, 5674-5684.

13. Li D, Sun WP, Zhou YM, et al. (2010) Chronic niacin overload may be involved in the increased prevalence of obesity in US children. World J Gastroenterol 16, 2378-2387. 
14. Slow S, Lever M, Chambers ST, et al. (2009) Plasma dependent and independent accumulation of betaine in male and female rat tissues. Physiol Res 58, 403-410.

15. Craig SA (2004) Betaine in human nutrition. Am J Clin Nutr 80, 539-549.

16. Smuckler EA, Koplitz M \& Sell S (1976) $\alpha$-Fetoprotein in toxic liver injury. Cancer Res 36, 4558-4561.

17. Aljanabi SM \& Martinez I (1997) Universal and rapid salt-extraction of high quality genomic DNA for PCR-based techniques. Nucleic Acids Res 25, 4692-4693.

18. Livak KJ \& Schmittgen TD (2001) Analysis of relative gene expression data using real-time quantitative PCR and the $2^{-\Delta \Delta C t}$ method. Methods 25, 402-408.

19. Robertson KD \& Jones PA (2000) DNA methylation: past, present and future directions. Carcinogenesis 21, 461-467.

20. Bird A (2002) DNA methylation patterns and epigenetic memory. Genes Dev 16, 6-21.

21. Daniel FI, Cherubini K, Yurgel LS, et al. (2011) The role of epigenetic transcription repression and DNA methyltransferases in cancer. Cancer 117, 677-687.

22. Pogribny IP \& Beland FA (2009) DNA hypomethylation in the origin and pathogenesis of human diseases. Cell Mol Life Sci 66, 2249-2261.

23. Robertson KD, Uzvolgyi E, Liang G, et al. (1999) The human DNA methyltransferases (DNMTs) 1, 3a and 3b: coordinate mRNA expression in normal tissues and overexpression in tumors. Nucleic Acids Res 27, 2291-2298.

24. Terentiev AA \& Moldogazieva NT (2013) Alpha-fetoprotein: a renaissance. Tumour Biol 34, 2075-2091.

25. Lim BH, Cho BI, Kim YN, et al. (2006) Overexpression of nicotinamide $N$-methyltransferase in gastric cancer tissues and its potential post-translational modification. Exp $\mathrm{Mol}$ Med 38, 455-465.

26. Yao M, Tabuchi H, Nagashima $\mathrm{Y}$, et al. (2005) Gene expression analysis of renal carcinoma: adipose differentiationrelated protein as a potential diagnostic and prognostic biomarker for clear-cell renal carcinoma. J Pathol 205, 377-387.

27. Xu J, Moatamed F, Caldwell JS, et al. (2003) Enhanced expression of nicotinamide $N$-methyltransferase in human papillary thyroid carcinoma cells. J Clin Endocrinol Metab 88, 4990-4996.

28. Sartini D, Muzzonigro G, Milanese G, et al. (2013) Upregulation of tissue and urinary nicotinamide $N$-methyltransferase in bladder cancer: potential for the development of a urine-based diagnostic test. Cell Biochem Biophys $\mathbf{6 5}$, 473-483.

29. Sartini D, Morganti S, Guidi E, et al. (2013) Nicotinamide $\mathrm{N}$-methyltransferase in non-small cell lung cancer: promising results for targeted anti-cancer therapy. Cell Biochem Biophys 67, 865-873.

30. Sousa MM, Krokan HE \& Slupphaug G (2007) DNA-uracil and human pathology. Mol Aspects Med 28, 276-306.
31. Hagen L, Peña-Diaz J, Kavli B, et al. (2006) Genomic uracil and human disease. Exp Cell Res 312, 2666-2672.

32. Focher F, Mazzarello P, Verri A, et al. (1990) Activity profiles of enzymes that control the uracil incorporation into DNA during neuronal development. Mutat Res 237, 65-73.

33. Muha V, Horváth A, Békési A, et al. (2012) Uracil-containing DNA in Drosophila: stability, stage-specific accumulation, and developmental involvement. PLoS Genet 8, e1002738.

34. Bateson PP, Rose SP \& Horn G (1973) Imprinting: lasting effects on uracil incorporation into chick brain. Science 181, 576-578.

35. Bateson PP, Horn G \& Rose SP (1975) Imprinting: correlations between behaviour and incorporation of $\left[{ }^{14} \mathrm{C}\right]$ uracil into chick brain. Brain Res 84, 207-220.

36. Young GS, Jacobson EL \& Kirkland JB (2007) Water maze performance in young male Long-Evans rats is inversely affected by dietary intakes of niacin and may be linked to levels of the $\mathrm{NAD}^{+}$metabolite cADPR. J Nutr 137, 1050-1057.

37. Shirley B (1984) The food intake of rats during pregnancy and lactation. Lab Anim Sci 34, 169-172.

38. Reagan-Shaw S, Nihal M \& Ahmad N (2008) Dose translation from animal to human studies revisited. FASEB $J \mathbf{2 2}$ 659-661.

39. Goldberg AS \& Hegele RA (2012) Severe hypertriglyceridemia in pregnancy. J Clin Endocrinol Metab 97, 2589-2596.

40. Cabrera-Rode E, Molina G, Arranz C, et al. (2006) Effect of standard nicotinamide in the prevention of type 1 diabetes in first degree relatives of persons with type 1 diabetes. Autoimmunity 39, 333-340.

41. Prousky JE (2005) Supplemental niacinamide mitigates anxiety symptoms: three case reports. J Orthomol Med $\mathbf{2 0}$, $167-178$

42. Beyer KH, Russo HF, Gass DR, et al. (1950) Renal tubular elimination of $N^{1}$-methylnicotinamide. Am J Physiol $\mathbf{1 6 0}$ $311-320$

43. Shibata K (1989) Fate of excess nicotinamide and nicotinic acid differs in rats. $J$ Nutr 119, 892-895.

44. MRC (1991) Prevention of neural tube defects: results of the Medical Research Council Vitamin Study. Lancet 338, $131-137$

45. Kirke PN, Daly LE \& Elwood JH (1992) A randomised trial of low dose folic acid to prevent neural tube defects. The Irish Vitamin Study Group. Arch Dis Child 67, 1442-1446.

46. Czeizel AE \& Dudás I (1992) Prevention of the first occurrence of neural-tube defects by periconceptional vitamin supplementation. $N$ Engl J Med 327, 1832-1835.

47. Czeizel AE, Dobó M \& Vargha P (2004) Hungarian cohortcontrolled trial of periconceptional multivitamin supplementation shows a reduction in certain congenital abnormalities. Birth Defects Res A Clin Mol Teratol 70, 853-861.

48. Czeizel AE (1999) Ten years of experience in periconceptional care. Eur J Obstet Gynecol Reprod Biol 84, 43-49. 